\title{
Efficacy of the travoprost/timolol fixed combination versus the concomitant use of travoprost $0.004 \%$ and timolol $0.1 \%$ gel formulation
}

This article was published in the following Dove Press journal:

Clinical Ophthalmology

\author{
Vassilios Kozobolis ${ }^{1,2}$ \\ Aristeidis Konstantinidis ${ }^{1,2}$ \\ Haris Sideroudi² \\ Miguel Teus ${ }^{3}$ \\ 'Department of Ophthalmology, \\ Democritus University of Thrace, \\ Alexandroupolis, Greece; ${ }^{2}$ Eye \\ Institute of Thrace (EIT), Democritus \\ University of Thrace, Alexandroupolis, \\ Greece; ${ }^{3}$ University of Alcala, \\ Madrid, Spain
}

Purpose: To compare the hypotensive effect of travoprost $0.004 \% /$ timolol $0.5 \%$ fixed combination (TTFC) to the concomitant use of travoprost and timolol $0.1 \%$ gel formulation (Trav + Geltim).

Materials and methods: Thirty-three patients (62 eyes) were enrolled and divided into two groups. Patients in group 1 (31 eyes) received the TTFC and patients in group 2 (31 eyes) received the concomitant treatment with Trav + Geltim. Patients on previous antiglaucoma treatment discontinued their drops for 2-4 weeks before starting their new treatment (TTFC or Trav + Geltim). The drops were instilled in the evening in group 1 and in group 2, the prostaglandin was installed in the evening, and timolol in the morning. IOP was measured at 1 and 3 months after the initiation of treatment at four time points during the day (09:00, 12:00, 15:00, and 18:00). Results: Both groups showed significant IOP reduction from baseline at all time points at 1 and 3 months. When the two groups were compared, group 2 showed slightly better hypotensive effect that reached statistical significance only at the 18:00 time point at both 1 and 3 months. Conclusion: Both the TTFC and the concomitant use of the travoprost/timolol gel showed similar hypotensive effect with the latter being slightly more potent in reducing the IOP.

Keywords: prostaglandin, timolol gel, glaucoma, fixed combination

\section{Introduction}

Medical therapy is the initial treatment option for the vast majority of cases of the open angle glaucomas. The use of the topical medications exposes the patient to the side effects of the active components of the drops as well as those of the preservatives. Monotherapy with a single drop is the recommended initial treatment of glaucoma. However, about half of these patients will require a second antiglaucoma agent after 2 years. ${ }^{2}$ Multiple drops on the contrary may not only have a negative impact on adherence ${ }^{3}$ but they can also expose the patients to higher amounts of preservatives, which play a fundamental role in the development of ocular surface disease in glaucoma patients. ${ }^{4}$ Research has shown that as many as $60 \%$ of glaucoma patients receiving topical therapy can develop ocular surface disease. ${ }^{5}$ The release of the fixed combinations has helped to improve adherence, reduce exposure to preservatives, and have similar hypotonic effect. ${ }^{6-8}$

The fixed combination of travoprost $0.004 \% /$ timolol $0.5 \%$ is marketed as DuoTrav (Alcon Laboratories, Fort Worth, TX, USA), and it has shown to have a more potent hypotensive effect than its individual constituents (travoprost monotherapy or timolol monotherapy). ${ }^{9}$ DuoTrav also had a higher hypotensive effect when switching from
Correspondence: Aristeidis Konstantinidis

Eye Institute of Thrace, Dragana 68131,

Alexandroupolis, Greece

Email aristeidiskon@hotmail.com 
Table I Demographic characteristics

\begin{tabular}{|c|l|l|}
\hline & TTFC & Trav + Geltim \\
\hline Age & & \\
\hline Mean & 65.25 & 65.24 \\
\hline Range & $57-79$ & $59-77$ \\
\hline Gender & & \\
\hline Male & 5 & 8 \\
\hline Female & 11 & 10 \\
\hline Diagnosis ( $=31$ eyes) & & \\
\hline OHT & 13 & 15 \\
\hline POAG & 18 & 16 \\
\hline Treatment-naive eyes & 8 & 6 \\
\hline Eyes receiving drops & 23 & 25 \\
\hline Baseline IOP (mean) & 26.83 & 26.63 \\
\hline
\end{tabular}

Abbreviations: OHT, ocular hypertension; POAG, primary open angle glaucoma; TTFC, travoprost-timolol fixed combination; Trav + Geltim, the concomitant use of travoprost and timolol $0.1 \%$ gel.

previous prostaglandin monotherapy. ${ }^{10}$ A study by Schuman et $\mathrm{al}^{11}$ has shown that DuoTrav is as effective as the unfixed combination of travoprost $0.004 \%$ administered in the evening and timolol $0.5 \%$ administered twice daily.

Geltim is a long-acting gel-forming carbomer that contains timolol $0.1 \%$. It was shown to be as effective as the standard aqueous timolol $0.5 \%$ with a safer cardiovascular profile. ${ }^{12,13}$

In this study, we compared the efficacy of the travoprosttimolol fixed combination (TTFC) with the concomitant use of travoprost and timolol 0.1\% gel (Trav + Geltim).

\section{Materials and methods}

\section{Study design}

This is a randomized prospective and comparative study that adhered to the tenets of the Declaration of Helsinki. The study was approved by the ethic committee of the University Hospital of Evros, Greece. All patients provided written informed consent before their participation in the study.

\section{Study population}

Thirty-three patients were enlisted, 16 (31 eyes) in the TTFC group (group 1) and 18 (31 eyes) in the Trav + Geltim group (group 2). The demographic characteristics of each group are summarized in Table 1.

Full ophthalmic examination was performed at the baseline visit, including medical history, distance best-corrected visual acuity (BCVA), IOP measurement, gonioscopy, slit lamp examination, fundoscopy, and Humphrey 24-2 whiteon-white perimetry. At each subsequent visit, BCVA and IOP measurements were taken and the patients were asked about possible side effects of the eye drops. Patients on previous antiglaucoma drops were asked to stop their medication. The washout period was 14 days for a-agonists and 30 days for b-blockers and prostaglandins. Patients on previous treatment had the IOP measured 14 days after the discontinuation of the drops. If the IOP was $\geq 35 \mathrm{mmHg}$, the patient was started on the appropriate antiglaucoma medication and was removed from the study.

Exclusion criteria included age $<18$ years, BCVA $<0.9$ $\operatorname{logMAR}$, glaucoma other than primary open angle, pseudoexfoliative and pigmentary, IOP at 09:00 $<23$ and $>35 \mathrm{mmHg}$, and previous ocular surgery (except for uncomplicated phacoemulsification at least 6 months before the baseline visit).

Treatment-naïve patients and patients selected for enrollment after discontinuation of their previous medical therapy were randomly assigned to the TTFC or the Trav + Geltim group.

After the baseline examination, the patients were reviewed at 1 and 3 months. The IOP was measured by two examiners (VK, AK) with an electronic Goldmann tonometer at the following time points during the day: 09:00, 12:00, 15:00, and 18:00. Patients in the TTFC group were asked to instill the drops at 21:00, and the patients in the Trav + Geltim group were advised to instill the prostaglandin at 21:00 and the timolol 0.1\% gel formulation at 08:00.

Statistical analyses of between-treatment group comparing the IOP responses with the drug regimens were performed using a paired $t$-test for both individual time points and the entire diurnal curve (average mean pressures measured throughout the day). The significance level was

Table 2 Mean IOP before treatment and after treatment ( $\mathrm{I}$ and 3 months) for both groups at different time points

\begin{tabular}{|c|c|c|c|c|c|c|c|c|}
\hline \multicolumn{5}{|l|}{ TTFC } & \multicolumn{4}{|c|}{ Trav + Geltim } \\
\hline Time points & \begin{tabular}{|l|} 
Before \\
treatment
\end{tabular} & I month & 3 months & $P$-value & $\begin{array}{l}\text { Before } \\
\text { treatment }\end{array}$ & I month & 3 months & $P$-value \\
\hline 09:00 & 26.83 & 17.6 & 17.34 & $<0.001$ & 26.63 & 16.93 & 17.5 & $<0.001$ \\
\hline $12: 00$ & 26.23 & 16.1 & 15.9 & $<0.001$ & 26.23 & 15.93 & 16.2 & $<0.001$ \\
\hline $15: 00$ & 26.04 & 16.13 & 16.03 & $<0.001$ & 26.04 & 15.96 & 15.86 & $<0.001$ \\
\hline $18: 00$ & 25.76 & 17.13 & 16.27 & $<0.001$ & 25.8 & 16.25 & 15.5 & $<0.001$ \\
\hline
\end{tabular}


Table 3 Mean IOP reduction from baseline

\begin{tabular}{|l|l|l|l|l|l|l|l|l|}
\hline & $\begin{array}{l}\text { Baseline } \\
\text { IOP }\end{array}$ & SD & $\begin{array}{l}\text { IOP at } \\
\text { I month }\end{array}$ & SD & P-value & $\begin{array}{l}\text { IOP at } \\
\mathbf{3} \text { months }\end{array}$ & SD & -value \\
\hline TTGC & 26.83 & 2.84 & 16.74 & 1.34 & $<0.0001$ & 16.39 & 0.68 & $<0.000$ I \\
\hline Trav + Geltim & 26.63 & 2.84 & 16.23 & 1.45 & $<0.0001$ & 16.27 & 0.66 & $<0.000 \mathrm{I}$ \\
\hline
\end{tabular}

Abbreviations: TTFC, travoprost-timolol fixed combination; Trav + Geltim, the concomitant use of travoprost and timolol $0.1 \%$ gel.

set at 0.05 . Within-treatment group, changes for individual time point were assessed using repeated measures ANOVA with Bonferroni correction. All statistical analyses were performed using MS-Excel Professional Plus 2010 and MedCalc statistical program (version 9.6.2.0; MedCalc Software, Mariakerke, Belgium).

\section{Results}

There was no significant difference in the mean IOP value between the two groups at baseline. The mean value was $26.83 \mathrm{mmHg}$ for the TTFC group and 26.63 for the Trav + Geltim group ( $P=0.626$ ). Both groups showed significant hypotensive effect from baseline at all time points at 1 and 3 months (Table 2). The mean IOP reduction from baseline was also significantly reduced (Table 3 , Figure 1 ). The mean IOP was calculated as the mean value of the measurements taken at the designated four time points.

When the two groups were compared, there was no significant reduction in the mean IOP at both 1 and 3 months from the baseline visit (Table 4, Figure 2). The mean IOP for the TTFC group at 1 month was $16.74 \mathrm{mmHg}$ and for the Trav + Geltim group $16.23 \mathrm{mmHg}(P<0.26)$. At 3 months, the mean IOP for the TTFC group was $16.39 \mathrm{mmHg}$ and for the Trav + Geltim group $16.27 \mathrm{mmHg}(P<0.44)$.

The two groups showed similar efficacy in lowering the IOP at all time points at 1 and 3 months except for the 18:00 time point where the Trav + Geltim group was more potent in lowering the IOP (Table 5, Figure 3). The mean IOP for the TTFC group at 18:00 was $17.13 \mathrm{mmHg}$ at 1 month vs $16.25 \mathrm{mmHg}$ for the Trav + Geltim group $(P=0.014)$ and $16.27 \mathrm{mmHg}$ vs $15.5 \mathrm{mmHg}$ at 3 months for the two groups, respectively $(P=0.002)$.

\section{Discussion}

In this study, we compared the efficacy of the fixed combination of travoprost $0.004 \% /$ timolol $0.5 \%$ (administered in the evening) to its constituents travoprost $0.004 \%$ (administered in the evening) and timolol $0.1 \%$ (administered in the morning). The efficacy and tolerability of the two separate drugs (travoprost and timolol gel-forming solution) have been investigated in previous articles ${ }^{14,15}$ and were not part of the this study.

Research has shown that fixed combinations are generally less potent in their hypotensive effect when compared with

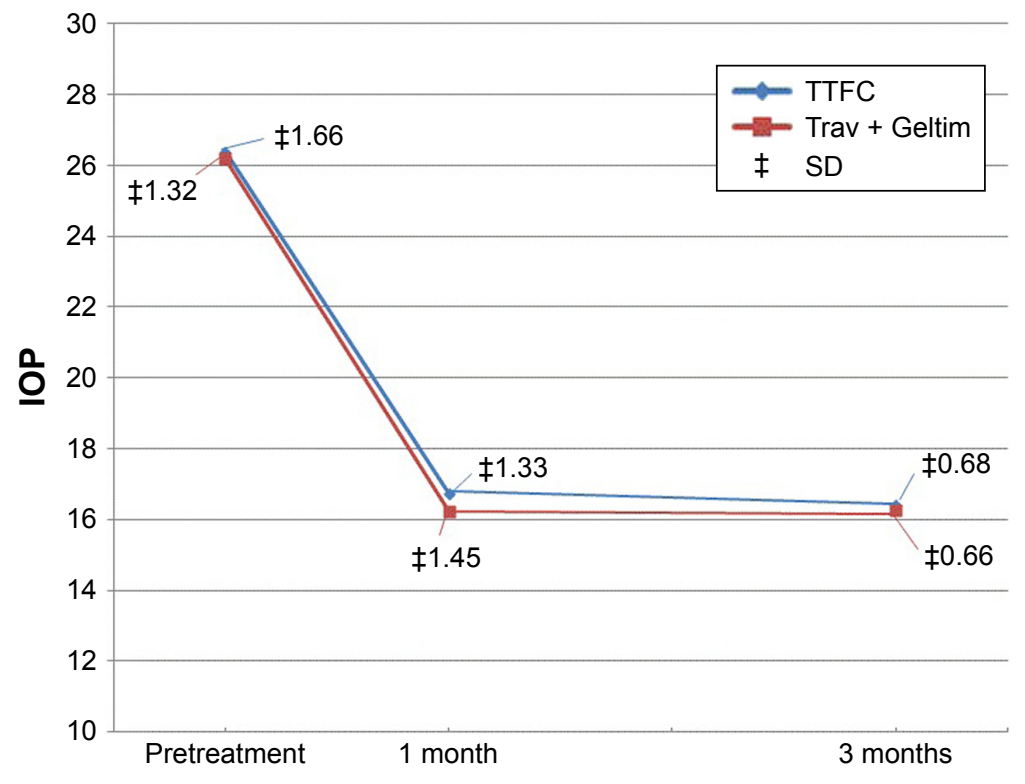

Figure I Mean IOP reduction from baseline for both groups.

Abbreviations: TTFC, travoprost-timolol fixed combination; Trav + Geltim, the concomitant use of travoprost and timolol $0.1 \%$ gel. 
Table 4 Mean IOP hypotensive effect of TTFC vs Trav + Geltim

\begin{tabular}{|l|l|l|l|l|l|l|}
\hline & Baseline IOP & P-value & I month & P-value & 3 months & -value \\
\hline TTFC & 26.83 & 0.626 & 16.74 & 0.26 & 16.39 & 0.44 \\
\hline Trav + Geltim & 26.63 & & 16.23 & & 16.27 & \\
\hline
\end{tabular}

Abbreviations: TTFC, travoprost-timolol fixed combination; Trav + Geltim, the concomitant use of travoprost and timolol $0.1 \%$ gel.

their constituents ${ }^{16}$ although this difference is insignificant and in some cases the fixed combination may provide a better hypotensive effect ${ }^{17}$ presumably due to the better convenience and adherence and the elimination of the washout effect of the second drop.

Our results have shown that the unfixed combination achieved a slightly better hypotensive effect although it did not reach statistical significance except for the 18:00 time point for which the Trav + Geltim group had lower IOPs at 1 and 3 months. A similar study by Nucci et al ${ }^{18}$ that compared the IOP-lowering effect of the fixed combinations of latanoprost, travoprost, and bimatoprost with timolol to the unfixed concomitant use of the prostaglandins and timolol $0.1 \%$ gel-forming carbomer showed that the concomitant use of the drops offered a significant hypotensive effect. The differences in the results can be explained by different methodology that we used in our study. The patients that were enrolled in our study were either treatment-naïve or if they had already been on drops they were asked to discontinue them before they were started on the fixed or the unfixed combination. In the study by Nucci et al, the patients were already on the fixed prostaglandin/timolol combination and were switched to the unfixed treatment without a washout period. Furthermore, Nucci et al did not have separate arms

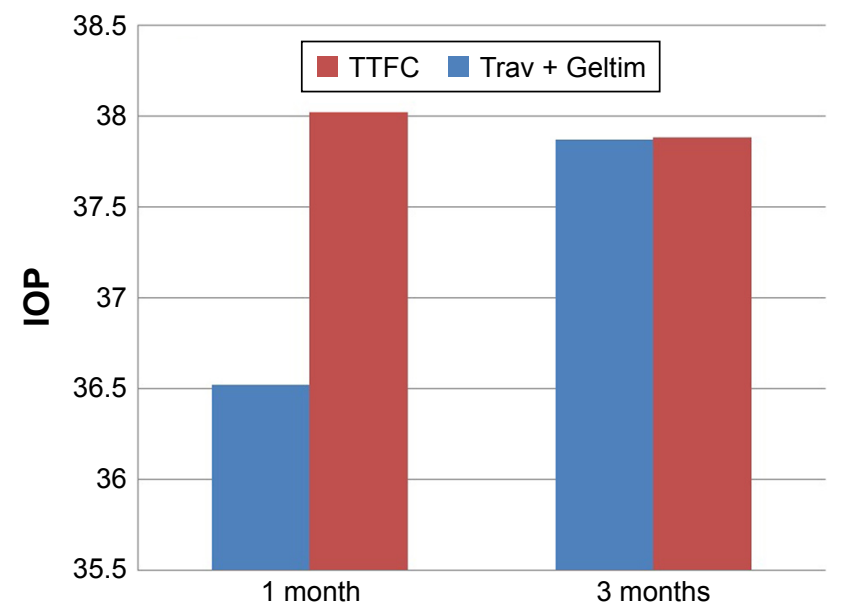

Figure $\mathbf{2} \%$ IOP reduction from baseline for the two groups at I and 3 months. Abbreviations: TTFC, travoprost-timolol fixed combination; Trav + Geltim, the concomitant use of travoprost and timolol $0.1 \%$ gel. for the fixed and the unfixed groups, but the hypotensive effect of the three fixed prostaglandin/timolol groups was compared with the unfixed combinations after the switch in the treatment. Finally, we enrolled 33 eyes in total, whereas in the study be Nucci et al there were nine patients in the travoprost/timolol group.

Two more studies have compared the efficacy of the travoprost/timolol fixed combination with its separate components. ${ }^{11,19}$ Both studies compared the efficacy of the fixed travoprost $0.004 \% /$ timolol $0.5 \%$ with the concomitant use of travoprost $0.004 \%$ instilled in the evening and timolol $0.5 \%$ administered in the morning. These studies confirmed that both regimes have equal efficacy although the concomitant use of the two drops showed a slightly better hypotensive effect.

The efficacy of the timolol $0.5 \%$ aqueous solution has been compared with the timolol $0.1 \%$ gel formulation. Both showed similar effects in terms of IOP lowering. The timolol $0.1 \%$ gel, however, was less adsorbed in the systemic circulation and affected the cardiovascular system to a lesser degree. The pulmonary function remained unaltered with both formulations. Thus, the timolol $0.1 \%$ gel had a higher risk-to-benefit ratio. ${ }^{13,20}$

In our study, the concomitant use of travoprost and timolol had slightly better hypotensive effect, which can be explained by the fact that the travoprost was instilled in the evening in the unfixed combination group although evidence has shown that travoprost has a similar hypotensive effect whether administered in the morning or in the evening. ${ }^{21}$ On the contrary, the use of timolol in a gel formulation in the morning can have its peak effect several hours after instillation and can explain the significant hypotensive effect at the 18:00 time point. The single morning dosage of the timolol gel avoids the washout effect of the second evening drop in the concomitant regimes with morning and evening timolol dosing.

In conclusion, the fixed travoprost/timolol combination provides similar hypotensive effect as the separate use of the two active components. The concomitant use of the drops had significant effect only in the early evening time point. 
Table 5 Comparison of the two groups at the individual time points

\begin{tabular}{|l|l|l|l|l|l|l|}
\hline \multirow{2}{*}{ Time points } & \multicolumn{2}{|l|}{ I month from baseline } & 3 months from baseline \\
\cline { 2 - 7 } & $\begin{array}{l}\text { Mean IOP } \\
\text { TTFC group }\end{array}$ & $\begin{array}{l}\text { Mean IOP Trav }+ \\
\text { Geltim group }\end{array}$ & P-value & $\begin{array}{l}\text { Mean IOP } \\
\text { TTFC group }\end{array}$ & $\begin{array}{l}\text { Mean IOP Trav }+ \\
\text { Geltim group }\end{array}$ & \begin{tabular}{l} 
P-value \\
\hline $9: 00$
\end{tabular} \\
\hline 17.6 & 16.93 & 0.27 & 17.34 & 17.5 & & 0.39 \\
\hline $15: 00$ & 16.1 & 15.93 & 0.94 & 15.9 & 16.2 & 0.25 \\
\hline $18: 00$ & 16.13 & 15.86 & 0.93 & 16.03 & 15.86 & 0.27 \\
\hline
\end{tabular}

Abbreviations: TTFC, travoprost-timolol fixed combination; Trav + Geltim, the concomitant use of travoprost and timolol $0.1 \%$ gel.

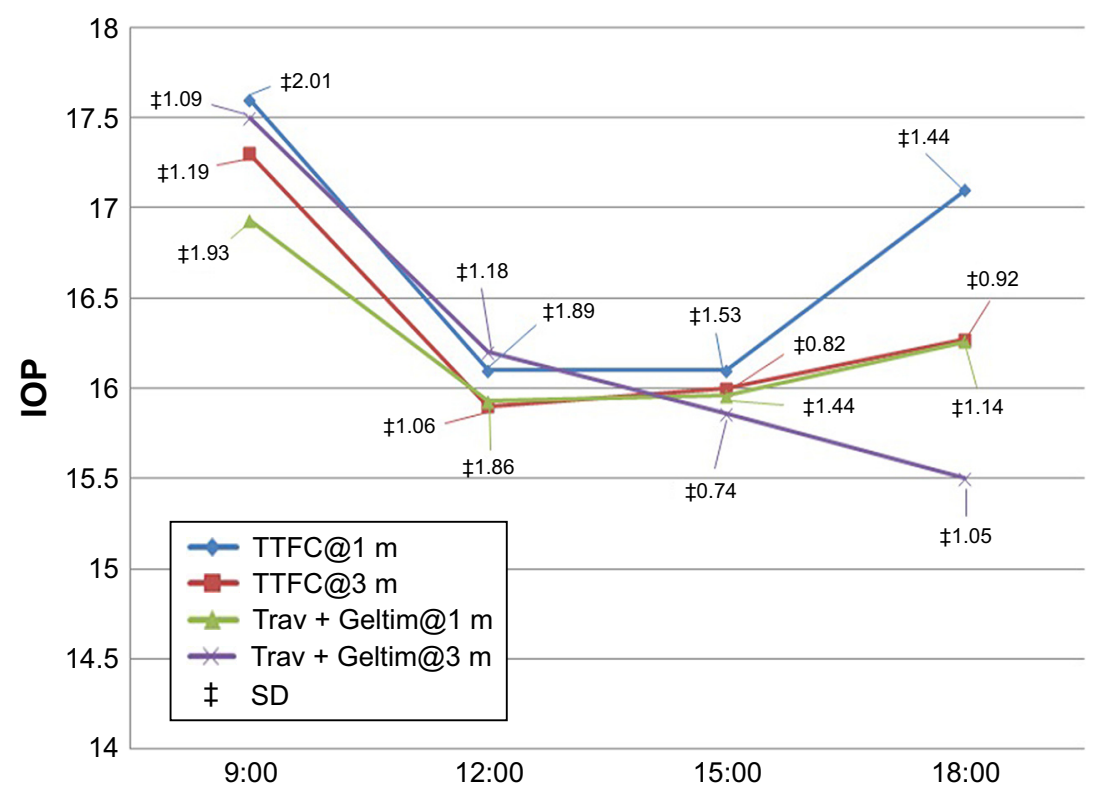

Figure 3 IOP measurements for the two groups at the determined time points at I and 3 months.

Abbreviations: TTFC, travoprost-timolol fixed combination; Trav + Geltim, the concomitant use of travoprost and timolol $0.1 \%$ gel.

\section{Disclosure}

The authors report no conflicts of interest in this work.

\section{References}

1. European Glaucoma Society. Terminology and Guidelines for Glaucoma. 4th ed. Italy: Savona; 2104.

2. Kobelt-Nguyen G, Gerdtham UG, Alm A. Costs of treating primary openangle glaucoma and ocular hypertension: a retrospective, observational two-year chart review of newly diagnosed patients in Sweden and the United States. J Glaucoma. 1998;7(2):95-104.

3. Robin AL, Covert D. Does adjunctive glaucoma therapy affect adherence to the initial primary therapy? Ophthalmology. 2005;112(5):863-868.

4. Anwar Z, Wellik SR, Galor A. Glaucoma therapy and ocular surface disease: current literature and recommendations. Curr Opin Ophthalmol. 2013;24(2):136-143.

5. Leung EW, Medeiros FA, Weinreb RN. Prevalence of ocular surface disease in glaucoma patients. J Glaucoma. 2008;17(5):350-355.

6. Higginbotham EJ. Considerations in glaucoma therapy: fixed combinations versus their component medications. Clin Ophthalmol. 2010; 4:1-9.

7. Barnebey HS, Robin AL. Adherence to fixed-combination versus unfixed travoprost $0.004 \% /$ timolol $0.5 \%$ for glaucoma or ocular hypertension: a randomized trial. Am J Ophthalmol. 2017;176:61-69.
8. Holló G, Topouzis F, Fechtner RD. Fixed-combination intraocular pressure-lowering therapy for glaucoma and ocular hypertension: advantages in clinical practice. Expert Opin Pharmacother. 2014;15(12):1737-1747.

9. Barnebey HS, Orengo-Nania S, Flowers BE, et al. The safety and efficacy of travoprost $0.004 \% /$ timolol $0.5 \%$ fixed combination ophthalmic solution. Am J Ophthalmol. 2005;140(1):1-7.

10. Costa VP, Moreira H, Paolera MD, de Moraes Silva MR. Efficacy and safety of travoprost $0.004 \%$ /timolol $0.5 \%$ fixed combination as transition therapy in patients previously on prostaglandin analog monotherapy. Clin Ophthalmol. 2012;6:699-706.

11. Schuman JS, Katz GJ, Lewis RA, et al. Efficacy and safety of a fixed combination of travoprost $0.004 \% /$ timolol $0.5 \%$ ophthalmic solution once daily for open-angle glaucoma or ocular hypertension. Am J Ophthalmol. 2005;140(2):242-250.

12. Uusitalo H, Kähönen M, Ropo A, et al. Improved systemic safety and risk-benefit ratio of topical $0.1 \%$ timolol hydrogel compared with $0.5 \%$ timolol aqueous solution in the treatment of glaucoma. Graefes Arch Clin Exp Ophthalmol. 2006;244(11):1491-1496.

13. Uusitalo H, Niño J, Tahvanainen K, et al. Efficacy and systemic sideeffects of topical $0.5 \%$ timolol aqueous solution and $0.1 \%$ timolol hydrogel. Acta Ophthalmol Scand. 2005;83(6):723-728.

14. El Hajj Moussa WG, Farhat RG, Nehme JC, et al. Comparison of efficacy and ocular surface disease index score between bimatoprost, latanoprost, travoprost, and tafluprost in glaucoma patients. JOphthalmol. 2018;2018:1-7. 
15. Delval L, Baudouin C, Gabisson P, Alliot E, Vincent B; Diamant Study Group. Safety and efficacy of unpreserved timolol $0.1 \%$ gel in patients controlled by preserved latanoprost with signs of ocular intolerance. J Fr Ophtalmol. 2013;36(4):316-323.

16. Konstas AGP, Mikropoulos D, Stewart WC. Fixed combination therapy in glaucoma. In: Shaarawy T, Sherwood M, Hitchings R, Crowston J, editors. Glaucoma. Philadelphia: Elsevier; 2009;1:566.

17. Francis BA, Du LT, Berke S, Ehrenhaus M, Minckler DS; Cosopt Study Group. Comparing the fixed combination dorzolamide-timolol (Cosopt) to concomitant administration of $2 \%$ dorzolamide (Trusopt) and $0.5 \%$ timolol - a randomized controlled trial and a replacement study. J Clin Pharm Ther. 2004;29(4):375-380.

18. Nucci C, Varesi C, Martucci A, et al. Efficacy of timolol $0.1 \%$ gel and a prostaglandin analog in an unfixed combination compared to the corresponding fixed combinations. Eur J Ophthalmol. 2013;23(5): $683-689$.
19. Hughes BA, Bacharach J, Craven ER, et al. A three-month, multicenter, double-masked study of the safety and efficacy of travoprost $0.004 \%$ / timolol $0.5 \%$ ophthalmic solution compared to travoprost $0.004 \%$ ophthalmic solution and timolol $0.5 \%$ dosed concomitantly in subjects with open angle glaucoma or ocular hypertension. J Glaucoma. 2005; 14(5):392-399.

20. Metheetrairut A, Leumsamran P, Rojananin S, Kitnarong N. A comparison of $0.1 \%$ timolol eye gel and $0.5 \%$ timolol eye drop in patients with chronic angle-closure glaucoma. J Med Assoc Thai. 2012;95(Suppl 4): S116-S122.

21. Konstas AG, Mikropoulos D, Kaltsos K, Jenkins JN, Stewart WC. 24-hour intraocular pressure control obtained with evening- versus morningdosed travoprost in primary open-angle glaucoma. Ophthalmology. 2006; 113(3):446-450.
Clinical Ophthalmology

\section{Publish your work in this journal}

Clinical Ophthalmology is an international, peer-reviewed journal covering all subspecialties within ophthalmology. Key topics include: Optometry; Visual science; Pharmacology and drug therapy in eye diseases; Basic Sciences; Primary and Secondary eye care; Patient Safety and Quality of Care Improvements. This journal is indexed on

\section{Dovepress}

PubMed Central and CAS, and is the official journal of The Society of Clinical Ophthalmology (SCO). The manuscript management system is completely online and includes a very quick and fair peer-review system, which is all easy to use. Visit http://www.dovepress.com/ testimonials.php to read real quotes from published authors. 